\title{
EL VERDE METROPOLITANO: UNA REVISIÓN DE LOS ESPACIOS ABIERTOS PÚBLICOS EN CLAVE PANDÉMICA PARA EL ÁREA METROPOLITANA DE BUENOS AIRES
}

LeONARdo Fernández

Investigador-docente del Instituto del Conurbano. Universidad Nacional de General Sarmiento lfernand@campus.ungs.edu.ar

\section{RESUMEN}

El texto reúne argumentos históricos, ecológicos y metropolitanos en la dotación de espacios abiertos públicos para el Área Metropolitana de Buenos Aires (AMBA) en perspectiva con el actual contexto pandémico. Primeramente, revisa antecedentes memorables sobre la temática contrastando ciertos imperativos higienistas epocales y contemporáneos frente al covid-19. En un segundo apartado, confluyente con el anterior, se define el concepto de "infraestructura ecológica" y se enumera a diferentes escalas diversos beneficios fisiológicos, sanitarios y ecológicos que esta noción supone. A modo de discusión, se mapean oportunidades en la geografía metropolitana, en el marco de la interfase pampeana y estuarina, para dotar de los espacios abiertos públicos.

Palabras clave: Ecología, Área Metropolitana de Buenos Aires, urbanismo, áreas verdes públicas, Covid-19.

\begin{abstract}
The text brings together historical, ecological and metropolitan arguments in the provision of public open spaces for the Metropolitan Area of Buenos Aires (AMBA) in perspective with the current pandemic context. Firstly, it reviews memorable antecedents on the subject, contrasting certain epochal and contemporary hygienist imperatives with covid-19. In a second section, the concept of "ecological infrastructure" is defined and the various physiological, health and ecological benefits of this concept are listed at different scales. By way of discussion, opportunities are mapped in the metropolitan geography, in the framework of the pampean and estuarine interface, to provide public open spaces.
\end{abstract}

Keywords: Ecology, Buenos Aires Metropolitan Area, urbanism, public green areas, Covid-19. 
EL VERDE METROPOLITANO: UNA REVISIÓN DE LOS ESPACIOS ABIERTOS PÚBLICOS EN CLAVE PANDÉMICA PARA EL ÁREA METROPOLITANA DE BUENOS AIRES

\section{RESUMO}

O texto reúne argumentos históricos, ecológicos e metropolitanos na disponibilização de espaços públicos abertos para a Área Metropolitana de Buenos Aires (AMBA) em perspectiva com o atual contexto pandêmico. Em primeiro lugar, ela revisa antecedentes memoráveis sobre $o$ assunto, contrastando certos imperativos epocais e higienistas contemporâneos com a covid-19. Em uma segunda seção, o conceito de "infra-estrutura ecológica" é definido e os vários benefícios fisiológicos, sanitários e ecológicos deste conceito são listados em diferentes escalas. Como forma de discussão, as oportunidades são mapeadas na geografia metropolitana, no âmbito da interface pampeana e estuarina, para proporcionar espaços públicos abertos.

Palavras-chave: Ecologia, Área Metropolitana de Buenos Aires, urbanismo, áreas verdes públicas, Covid-19.

\section{INTRODUCCIÓN}

Un organismo microscópico ha puesto patas para arriba la vida en las ciudades de todo el globo. El impacto de la globalización del virus covid-19 colocó en el foco el manejo epidemiológico de las grandes ciudades. En Argentina, el epicentro de contagios es el Área Metropolitana de Buenos Aires (AMBA), conformado por la Ciudad Autónoma de Buenos Aires (CABA) y 40 partidos conurbados de la Provincia de Buenos Aires. Hoy en día en el AMBA habitan más de 15 millones de habitantes, representando el $37 \%$ de la población del país en un entorno urbanizado cercano a $2.500 \mathrm{~km} 2$, menor al $1 \%$ del territorio nacional (INDEC, 2010). Esta concentración urbana en la interfase continental y rioplatense, supuso una transformación del entorno natural y rural que alcanza un marco físico extraordinario: sólo en las últimas cinco décadas la ocupación metropolitana ha llegado a duplicar toda la huella urbana de 430 años, iniciada en 1580 con la fundación de Juan de Garay (Fernández, 2016).
Actualmente agencias gubernamentales, científicas y comunicacionales recomiendan respetar la distancia física interpersonal o "distancia social" y la realización de actividades de aglutinamiento social en espacios abiertos, como medidas para evitar la transmisión y propagación del covid-19. ${ }^{1}$ Es que mientras se ejecutan campañas de inmunización del virus, la población está bajo la amenaza del pandémica, sobre todo con la aparición de nuevas variantes del virus que complejizan el cuadro de crisis sanitaria y socio-económica. Sin embargo, esa distancia social de al menos 1 metro, tanto en espacios cerrados como abiertos, tal como recomienda la Organización Mundial de la Salud, depende de muchos factores como la densidad poblacional y disponibilidad de espacios públicos. Ciertamente, la pandemia viene a

1 Además del cumplimiento de distancia social, hay apelativos a otras medidas sanitarias como el uso de tapabocas, lavarse las manos, toser en codos, entre otras. 
revelar el déficit y la desigualdad en el acceso a los espacios abiertos: en la región encontramos una relación de espacios verdes de 3,2 m2/hab., muy lejos de los 10m2/hab fijados en estándares internacionales y la normativa vigente.

Ahora bien, desde un abordaje regional de esta cuestión es posible reunir referencias memorables que acontecieron, por diferentes circunstancias, en tiempos de auténticas crisis sociales, de cambios de paradigmas, de contundentes transformaciones materiales, en períodos de ruptura política, económica y social. Quizás al ponerlos en perspectiva, transporten en el actual tiempo histórico los debates metropolitanos y las prácticas del urbanismo y paisajismo, brindando valores y puntos de vistas a la hora de analizar la dotación de espacios libres abiertos. Y este es el aspecto que interroga el texto: ¿qué antecedentes históricos sobre los espacios abiertos es posible reunir de la geografía metropolitana?, ¿qué tipos de espacios regionales podrían amortiguar el impacto de la pandemia? Una base fundamental para ampliar la distancia social, en el marco de una gestión de los espacios abiertos metropolitanos que enfrente efectos de la pandemia, es lo que podemos definir conceptualmente como una infraestructura ecológica. Y aclaremos que la palabra ecológica que se destaca refiere no sólo a esas infraestructuras asociada a los espacios «verdes» como plazas, parques y reservas; sino también de los espacios «azules», cuando pensamos en litorales, cursos o cuerpos de agua; incluso, los espacios "grises», de las infraestructuras del transporte, vial o edilicias de una ciudad (Boada y Capdevilla, 2000).

La hipótesis que recorre el texto es que ciertas prácticas higienistas memorables en relación al verde metropolitano permiten colocar en el contexto actual el ensayo de diferentes formas ecológicas para el AMBA, aunque dotando de valores y significados propios si se piensan en clave pandémica. Metodológicamente, se realiza en un primer apartado una revisión historiográfica de los espacios verdes en la geografía pampeana, metropolitana y rioplatense. En un segundo apartado, relacionado con el anterior, se define el concepto de infraestructura ecológica y se enumera los beneficios a diferentes escalas que esta noción supone para la población en tiempos de pandemia. A modo de discusión, y valiéndose de herramientas de teledetección y Sistema de Información Geográfica (SIG), se mapean oportunidades para dotar de infraestructura ecológica en la geografía metropolitana en su interfase pampeana y estuarina.

\section{BUENOS AIRES PAMPEANA, METROPOLITANA Y RIOPLATENSE}

Desde el abordaje de la historia urbana, diferentes autores privilegian como objeto de estudio las "representaciones" sobre la ciudad, adoptando problemas, temas y matices diversos: ya sea confrontando ideas y prácticas a la hora de analizar cómo se plasman los proyectos y los planes para la ciudad (Novick, 1992); o revalorizando el rol de los técnicos y funcionarios estatales en la concepción y los modos de intervenir en la ciudad (Liernur, 2001); inclusive planteando una "tensión de enfoques" que, en perspectiva de la historia cultural urbana, supone el ejercicio de interrogar, colocar en perspectiva y ofrecer puntos de vista en dimensiones intelectuales, figurativas y representacionales sobre las ideas de la ciudad, incluso sobre cómo la ciudad real 


\section{EL VERDE METROPOLITANO: UNA REVISIÓN DE LOS ESPACIOS ABIERTOS PÚBLICOS EN CLAVE PANDÉMICA PARA EL}

ÁREA METROPOLITANA DE BUENOS AIRES

se va conformando, a la vez, como producto de esas ideas (Gorelik, 2004). En esas perspectivas se reconoce estudios que han tematizado específicamente los espacios verdes públicos para Buenos Aires y su región en diversos contextos históricos (Gorelik, 1999; Caride Bartrons 2004; Ballent, 2005; Fernández, 2020).

$\mathrm{Al}$ iniciar un recorrido por experiencias memorables sobre los espacios verdes a escala metropolitana de Buenos Aires aparece, por antonomasia, Domingo Faustino Sarmiento con la construcción del Parque Tres de Febrero (1875), popularmente conocido como Bosque de Palermo. Pensemos que hasta comienzos del siglo XVIII el higienismo y el embellissement (u ordenamiento paisajístico) europeo ofrecían los parques escénicos para la nobleza y una ascendente elite burguesa, en espacios como Versalles en París, Hyde Park en Londres y Tiergarden en Berlín. Recién a comienzos del siglo XIX fueron incorporados al uso público. En América el primer parque escénico público fue

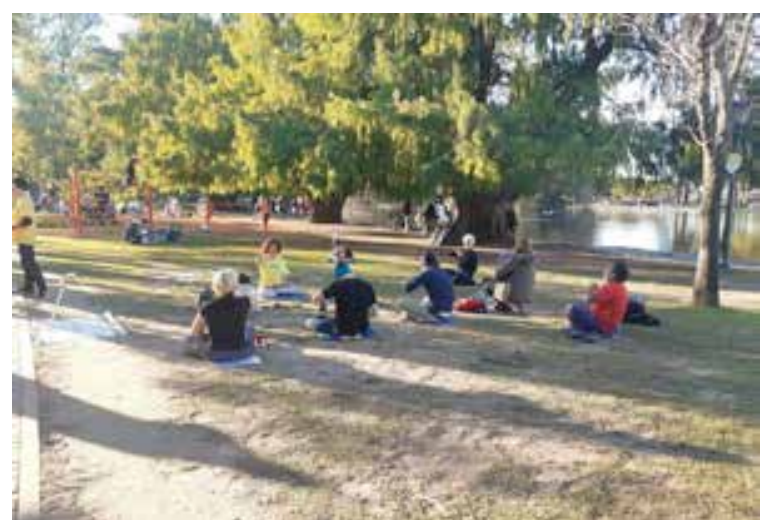

Fig. 1. Los Bosques de Palermo. Una escena de los Bosques de Palermo en pandemia. Los espacios abiertos públicos son utilizados para el desarrollo de diversas prácticas: durante una jornada se pueden ver personas realizando rutinas de ejercicios, yoga, cumpleaños infantiles y reuniones de amigos y familiares. Foto: Leonardo Fernández el Central Park (1850) en Nueva York. Probablemente, Sarmiento se inspiró en este parque durante su permanencia en los Estados Unidos cuando estableció el Parque Tres de Febrero en una geografía excéntrica bonaerense. Esta zona hacia fines del siglo XIX era una franja pantanosa sobre la costa rioplatense al que Juan Manuel de Rosas, gobernador bonaerense, transformó como paseo forestado con un gran edificio para atender los asuntos públicos en primavera y verano. Sarmiento, tras las epidemias de fiebre amarilla y cólera que diezmaron Buenos Aires, mandó a ocupar una franja amplia de terrenos bajos, rellenando con escombros y basuras, en el encuentro de la pampa con el Río de la Plata. De esa manera se desplegó un higienismo decimonónico en Buenos Aires con una operación territorial y culturalista que articulaba el proyecto reformista de "civilizar" un espacio teorizado como "bárbaro" mediante el impulso de parques y lagos, y a la vez, edificios educativos (Gorelik, 1999).

Ese espacio público resulta hoy día en una "válvula de escape" de la ciudadanía para llevar a cabo prácticas al aire libre. Sin embargo, las condiciones actuales del acceso al espacio abierto público son muy desiguales en el AMBA. No sólo por intereses de los actores encargados de la producción del espacio urbano, sino que deviene de procesos de larga data que fueron configurando zonas con buena dotación y calidad de espacio público (integradas) y zonas de mala dotación y calidad de espacio público (segregadas), que se encuentran marginadas y excluidas. De acuerdo a datos de superficie y población de cada municipio según zonas del AMBA, la disponibilidad de plazas y plazoletas, solo cubre el $25 \%$ (1.168 ha.) de la necesidad, establecida por la 
normativa de uso del suelo. Respecto a la disponibilidad de Parques urbanos, tanto locales como regionales, la superficie existente cubre el 36\% (3.049 ha) de la necesidad total. De ahí que se encuentran con mayor necesidad de superficie destinada a plazas, plazoletas o espacios libres vecinales, en orden decreciente, las Zonas Norte, Oeste, CABA y Sur del AMBA (Garay y Fernández, 2013).

Entre fines de la década de 1920 y la década de 1930 los textos de Carlos María de Della Paolera instalan el urbanismo como disciplina y los imperativos de ampliación de los espacios verdes o libres en la planificación para el Gran Buenos Aires. Con posgrados en la escuela de urbanismo organicista de París Della Polera (1933) se esforzaba en demostrar que "Buenos Aires no tiene noción del espacio libre" argumentando que se tuvo históricamente un concepto erróneo de la razón de ser del "organismo urbano" en su verdadera y doble función: "higiénica" y "estética". De ahí que concibe a los espacios libres como "pulmones" de la ciudad (Della Paolera, 1977). Esa relación orgánica entre ciudad-entorno ya encontraba aportes en Buenos Aires en los proyectos de Forestier y Carrasco de la Comisión de Estética Edilicia (1925), que en clave d'embellissement et d'extension afiliado al paisajismo francés dan forma al encuentro de la ciudad y el río. Sin embargo, Della Paolera insistía en sus ideas que acaso tuvieron expresión material con la fáustica Avenida 9 de Julio de 140 metros de ancho, demoliendo manzanas enteras del "asfixiante" centro de Buenos Aires, dando paso con el tiempo a una avenida-parque para el "Gran Buenos Aires", es decir, a escala regional (Novick, 2011).
Escribe Della Paolera (1934) que "la ciudad como el árbol no puede desligarse de la tierra que lo sustenta". También aparece el rechazo a los problemas de la ciudad-carbón, expresión que alude a esas fábricas humeantes y la vivienda obrera en íntima relación de promiscuidad. Aunque admitamos en el urbanismo organicista vernáculo, cierto talante eugenésico influenciada en la noción Blut und Boden (sangre y tierra) spengleriano, presente en el escenario cultural sudamericano de comienzos del siglo XX (Outtes, 2002). De acuerdo a esa noción, vivir bajo precarias condiciones físicas suponía que sucesivas generaciones serían cada vez más enfermas, incapaces para el trabajo e inútiles para la sociedad. Esta representación es tan influyente, que se expresa en el manifiesto del "Símbolo del Urbanismo" con elementos naturales con el sol, el aire y la vegetación en "una cruzada de regeneración de las condiciones de vida" (Della Paolera, 1934).

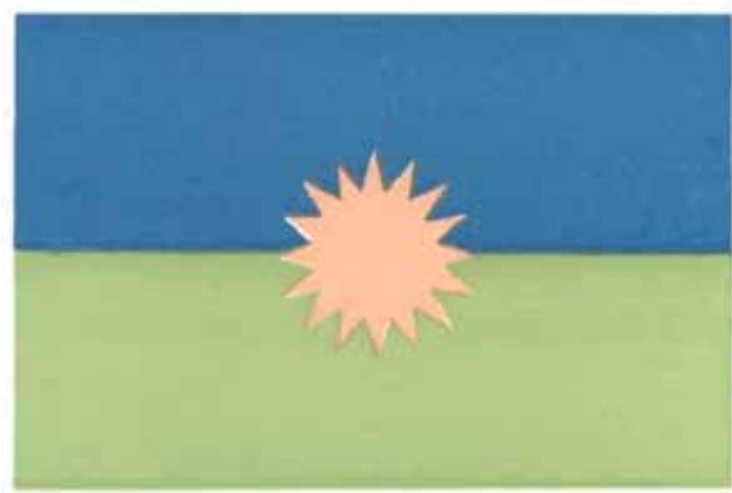

Fig. 2. El símbolo del urbanismo. La bandera, que consta de dos franjas horizontales, la superior de color azul profundo representa el "aire", el verde la "vegetación” y en el centro el "sol", realizada para enarbolar como un símbolo del urbanismo el día 8 de noviembre de cada año. Fuente: Carlos María Della Paolera. Reproducción del manifiesto original del símbolo del urbanismo. Noviembre de (Della Paolera, 1934). 


\section{EL RIO}

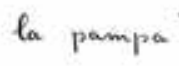

la cueded

Fig. 3. Buenos Aires tiene un límite natural. "Proyecto de un aeropuerto en el río" de Amancio Williams puesta en diálogo con la Cité des Affaires de Buenos Aires sobre el límite rioplatense y la infinitud de la Pampa resumida en el dibujo nocturno de los rascacielos en el encuentro del denso Río de la Plata. Fuente: Le Corbusier et al. (1947).

Cuando pensamos en la ciudad la imagen que quizás más viene a la cabeza tenga como elementos el cemento, vidrio, ladrillos o pavimento. Irónicamente, la imagen que se enarbola en el Símbolo del Urbanismo hay una respuesta a las consecuencias en el medio físico (y social) de la industrialización y la urbanización, de ahí que asignaban fuertemente el apelativo a simbologías muy elementales de la naturaleza con las que intervenir en el urbanismo. Indudablemente, cobran un lugar protagónico en tiempos pandémicos, bajo el apelativo de ciudades insalubres en pos de un balance con la naturaleza encuentra en los parques urbanos de hoy a cuerpos que buscan sol, agua y verde, en una imagen simbólica del urbanismo organicista que quizás en su vida Della Paolera hubiera soñado.

En contrapartida a ese urbanismo organicista desembarca en Argentina desde fines de la década de 1920 Le Corbusier con la "estética de la máquina", tábula rasa, nihilista, aunque con adopción de elementos regionalistas en algunas realizaciones. Quizás con el convencimiento de que Buenos Aires se contempla en la encrucijada pampeana y rioplatense, ya no como una ciudad industrial sino financiera, reposando en la tecnología de la arquitectura moderna de ese momento. Le Corbusier escribe: “[...] el sol y la topografía son los elementos más importantes para hallar la profunda línea de cada civilización" (Le Corbusier, 1941). También dirá: “[...] el urbanismo es una ciencia en tres dimensiones, y no dos dimensiones". En esa clave culturalista argumenta que es "haciendo intervenir el elemento altura como se dará solución a las circulaciones modernas y a los esparcimientos, por el aprovechamiento de los espacios libres así creados" (Le Corbusier, 1954). Esta formulación del urbanismo está impresa en la Carta de Atenas (1933) proclamada por el movimiento ideológico, tecnocrático y artístico que, de alguna manera, encarna la figura de Le Corbusier. En ese urbanismo reposa en el concepto del zoning, por analogía con la racionalización del sistema de producción industrial. De ahí las cuatro funciones que especializar: "habitar, trabajar, recrear y circular", análogamente traducida la ciudad en una ingeniería de cuerpos en movimiento que se igualan al tránsito en una cadena de montaje de una fábrica.

La pandemia actual ha puesto en de- 
bate la densificación y verticalización de arquitecturas que consagra el urbanismo funcionalista, siendo cuestionado actualmente por los desafíos de compatibilizar medidas de distancia social y de atender el factor "miedo" que suponen la diversidad de actividades y la proximidad de la población. En rigor, en ese debate se interpela al modelo de ciudad compacta consagrado ecológicamente como eficiente (Rueda, 1995, Batty, 2008, Alberti, 2009). Curiosamente, la crítica ecológica al zoning de esta corriente viene de la mano de la baja densidad y la hiper circulación que propone, y el consecuente aumento de entropía que supone. Aunque parecería que la pandemia introduce una nueva legitimidad para la baja densidad con el aislamiento social de base sanitaria, anclado en el desarrollo del teletrabajo (Corti, 2021).

Recordemos que durante el período de reformas sociales del primer peronismo (1944-1955) tuvo lugar expropiaciones de grandes extensiones de tierras que dieron paso a realizaciones de envergadura material y simbólica para el conurbano bonaerense como los Bosques de Ezeiza y el Parque Pereyra Iraola. Entre ellas se destaca la "operación Ezeiza” de seis mil hectáreas, realizada en una zona suburbial de bañados y usos ganaderos, configurando una gran traza vial de conexión al nuevo aeropuerto internacional donde ubicaba la "puerta de entrada al país en la pampa", desplazando anteriores propuestas como la de Amancio Williams (anexa al Plan Director para Buenos Aires de Le Corbusier 1947), que anteponía al Río de la Plata como lugar de radicación del aeropuerto. Se completaba la operación Ezeiza con extensos parques públicos, balnearios populares y una inmensa reserva forestal para los trabajadores. A su vez, se plasma el iconográfico barrio jardín Ciudad Evita (La Matanza) con una trama urbana y rodeando un "fuelle verde" que adquiere valor patrimonial con la imagen de Evita representada en el pavimento. Agreguemos que el Bañado de Flores en la Capital Federal fue la pieza incompleta de la operación Ezeiza como corolario del derrocamiento de Juan Domingo Perón en 1955 (Ballent, 2005). Acaso de ese período de trascendentes reformas sociales (y urbanas) se conservan significantes hoy día en aquellos pilares privilegiados de la acción pública como el trabajo y la vivienda. Específicamente reconocibles en la implementación de políticas y nuevos instrumentos para garantizar el acceso a suelo urbano digno para vivir, como es la aplicación de la recuperación de valorización inmobiliaria, conocida también como "plusvalía urbana”. Dicho instrumento cuenta la Provincia de Buenos Aires (Ley 14.449/12 de Acceso Justo al Hábitat), siendo una herramienta de promoción del acceso justo al hábitat para los ciudadanos bonaerense (Scatolini, Duarte y Hutton, 2020), y poniendo de relieve en el "hábitat popular" como un ámbito esencial de la acción estatal.

A fines de la década de 1970 se impone manu militari el denominado Cinturón Ecológico Área Metropolitana (CEAMSE) con una empresa estatal que ensaya un plan ambicioso para crear un green belt de 30.000 hectáreas en el conurbano, en forma de "muralla verde", de "cortina forestal" para "oxigenar" Buenos Aires, aprovechando para tal fin las conexiones del ambiente natural: la selva en galería del río de la Plata, el parque Pereyra Iraola, los Bosques de Ezeiza, la presa Rogge- 


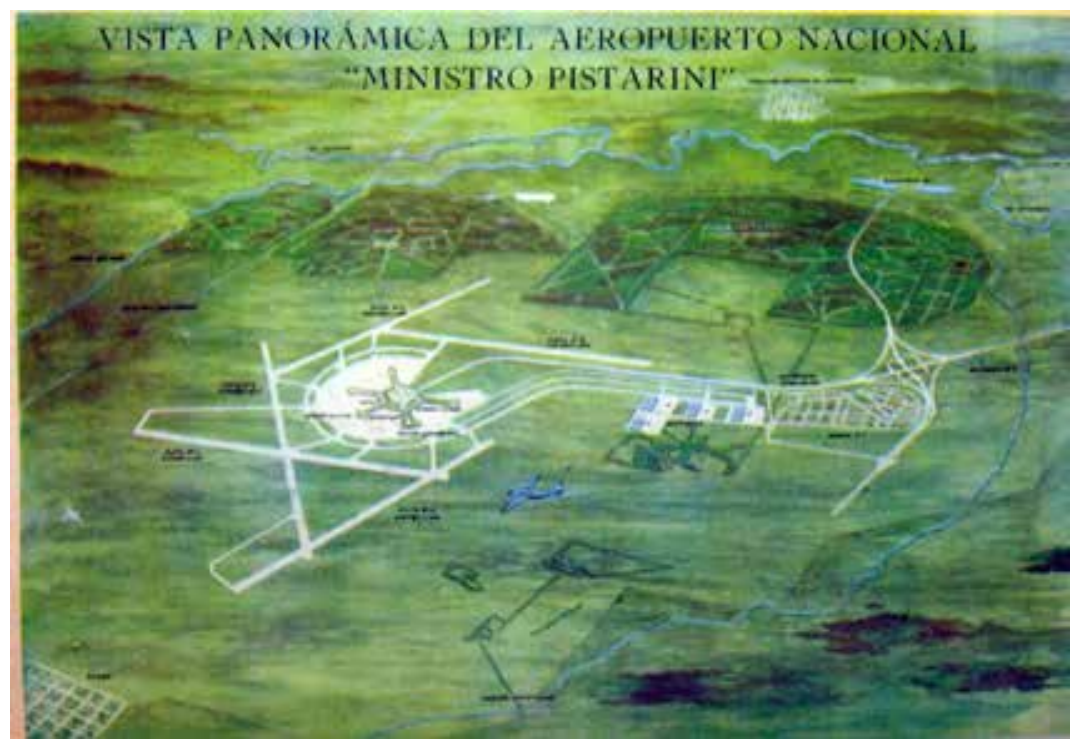

Fig. 4. La operación Ezeiza. La imagen del plano de la Operación Ezeiza donde las condiciones de los planteos territoriales se daban en un clima de época de reformas sociales dominados por la retórica programática de planes nacionales, de algún modo, marcando las posibilidades del urbanismo. La figura muestra la ubicación relativa tres proyectos de valor historiográfico y metropolitano, ilustrada por contrastes -entre Capital Federal y Conurbano Bonaerense-, y elementos de paisaje forestado que se integran -como el barrio parque Ciudad Evita, la Autopista Ricchieri y el aeropuerto internacional. Extraído de Presidencia de la Nación (1950). sividad de la vida de la ciudad", "encauzar a los jóvenes a través del deporte" y recurrir a 'una 'muralla verde' para controlar la expansión urbana sin límite" (Fernández, 2020). Si bien el cinturón ecológico no llegó a completarse de forma integral, sí logró plasmar durante el régimen militar y con la vuelta a la democracia, una parte de la formulación prevista como una obra-suma compuesta de rellenos sanitarios para el tratamiento de la basura, grandes parques recreativos y un tramo de autopista de conexión metropolitana. ro, franja del Río de la Reconquista, Campo de Mayo y el Delta del Paraná. Un camino parque, aunque luego adoptando forma de autopista, denominada Camino del Buen Ayre uniría la costa rioplatense, la pampa y el delta a través de una gran reserva verde. En rigor, el programa territorial se trató de una versión de reserva verde pública inspirada a imagen de los Bosques de Palermo de Sarmiento (Laura, 1978). Los imperativos de seguridad interna de la década de 1970 le dotan a esos grandes espacios verdes ciertos significantes del período histórico que, según el primer equipo técnico del CEAMSE, proponen "restablecer el equilibrio a fin de reducir la agre-
Esa impronta del período dictatorial que se reconoce en los espacios verdes a escala metropolitana hoy día resignificados, y dotando de nuevos sentidos en tiempo pandémico. A los parques recreativos que actualmente administra la actual CEAMSE se agregan varias iniciativas municipales con reservas naturales urbanas (San Miguel, Hurlingham, Morón e Ituzaingó) asociadas a la cuenca del Río Reconquista. También está en desarrollo la iniciativa nacional del Ministerio de Defensa y la Secretaría de Ambiente y Desarrollo Sustentable con la Reserva Ambiental de la Defensa Campo de Mayo (Decreto N. 


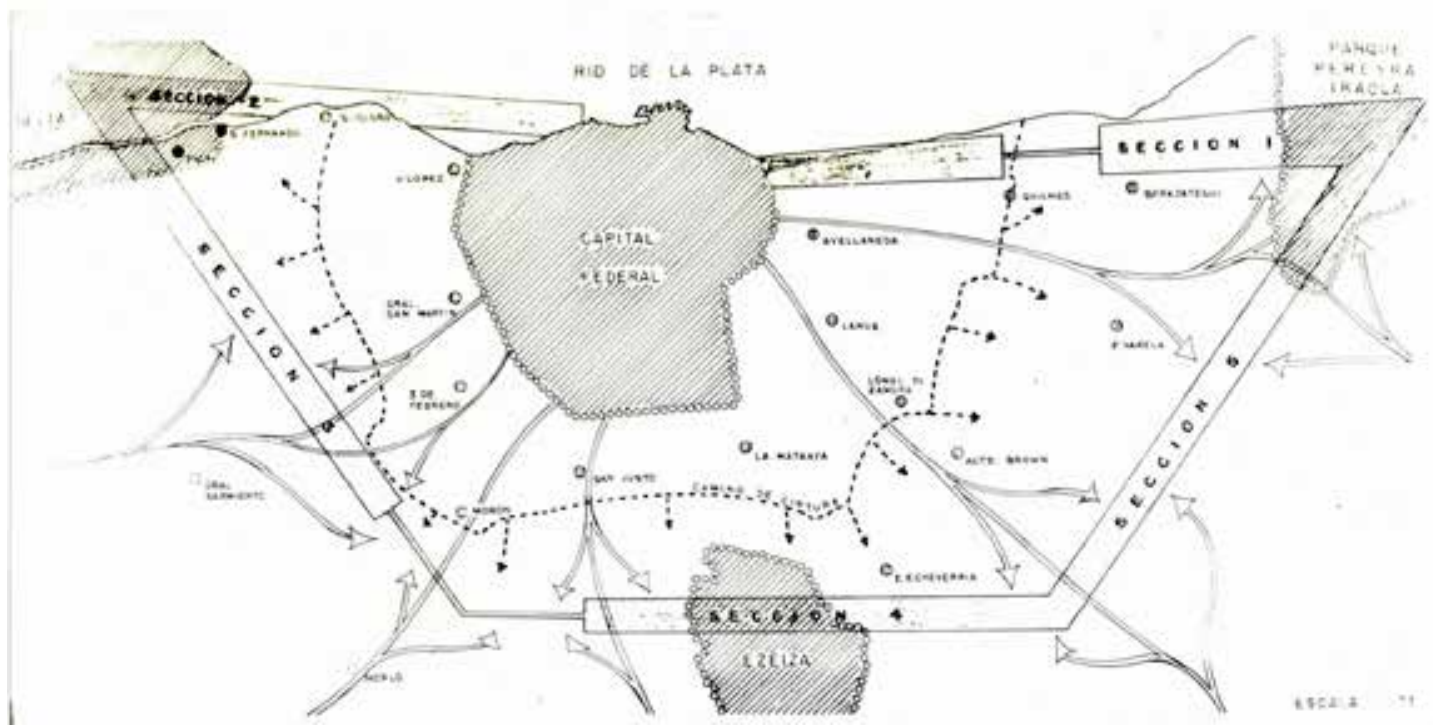

Fig. 5. Un cinturón ecológico en el área metropolitana. Tres dimensiones del cinturón ecológico (1978), una cintura física en la metrópolis (green belt), un anillo vial metropolitano (park-way) y rellenos sanitarios (landfill) como proyecto de metrópolis a escala regional. Fuente: Archivo histórico de la Biblioteca del CEAMSE.

1056/2018) con una extensión de más de 1300 hectáreas.

Ahora bien, esta revisión de experiencias memorables da cuenta de diversas ideologías urbanísticas en el tema de estudio y diferentes proyectos políticos en el territorio, atendiendo a problemas, apelando a discursos e interviniendo en el medio físico en diferentes épocas. El tiempo histórico actual está marcado por la lucha contra el covid-19 que se impone con nuevos imperativos higienistas en relación con los espacios abiertos a nivel del AMBA, como en las grandes ciudades de todo el globo, aunque se apoyen en prácticas tradicionales, tal como pudimos dar cuenta. Para mediados de mayo de 2021 el Ministerio de Salud de la Nación reportaba que aproximadamente 1 de cada 2 contagios de covid-19 del país se dan en el AMBA. De hecho, es la región con mayores restricciones de circulación y de suspensión de actividades, dadas las altas tasas de contagios y letalidad en comparación a otras regiones del país. De ahí que por decreto de necesidad de urgencia el estado nacional ordene a las instancias gubernamentales involucradas (Nación, Provincia de Buenos Aires, Ciudad Autónoma de Buenos Aires y municipios bonaerense) cumplan severos criterios sanitarios, sacrificando el normal desarrollo de actividades económicas, de movilidad y educativas, no sólo por tener focos de contagios en geografías urbanas con hacinamiento social crítico sino también serios vectores de transmisión a través del transporte metropolitano. Precisamente, en momentos en que gana terreno el imperativo 
EL VERDE METROPOLITANO: UNA REVISIÓN DE LOS ESPACIOS ABIERTOS PÚBLICOS EN CLAVE PANDÉMICA PARA EL ÁREA METROPOLITANA DE BUENOS AIRES

epocal de la distancia social y el mayor uso de los espacios abiertos. Efectivamente, en el AMBA encontramos una relación de espacios verdes muy deficitaria de menos de $3,2 \mathrm{~m}^{2}$ por habitantes, lejos de los estándares de $10 \mathrm{~m}^{2}$ en la Provincia de Buenos Aires por el decreto-ley ${ }^{2}$ dictatorial vigente (DL 8912/1977), inclusive de los parámetros internacionales de hasta los $15 \mathrm{~m}^{2}$ recomendados por la OMS (Garay y Fernández, 2013). Es en tal sentido que se puede interpretar cómo el concepto de la denominada infraestructura ecológica de concepción sistémica puede resultar un dispositivo de cierta forma novedoso aunque, como examinaremos, con ideas y prácticas que proyectan referencias históricas acontecidas en la geografía pampeana, metropolitana y rioplatense. Exploremos esta idea.

\section{ELEMENTOS DE UNA INFRAESTRUCTURA ECOLÓGICA FRENTE A LA PANDEMIA}

Décadas de estudios en "ecología urbana" (Rueda, 1995; Bettini, 1998; Terradas, 2001; Batty, 2008; Alberti, 2009; Di Pace y Caride, 2012, entre otros) han definido, con enfoques y matices diversos, que la "ciudades son ecosistemas" siendo conceptualizadas como sistemas complejos que se desarrollan en interrelación de componentes biofísicos y socio-económicos en

2 El Decreto-Ley 8.912/1977, en el Artículo 13 establece parámetros cuantitativos, fijando en $10 \mathrm{~m} 2$ / habitantes para núcleos urbanos, distribuidos en: a) 3,5 $\mathrm{m} 2 /$ hab. Plazas, plazoletas o espacios libres vecinales, b) 2,5 m2/hab. Parques urbanos y c) $4 \mathrm{~m} 2 / \mathrm{hab}$. Parques regionales. Por su parte, la Organización Mundial de la Salud (OMS) establece, como relación entre población y espacios verdes, un mínimo de $9 \mathrm{~m} 2 / \mathrm{hab}$ y $15 \mathrm{~m} 2 / \mathrm{hab}$. como estándar deseable. escala, tamaño y forma. Específicamente, hay investigaciones que han centrado en la denominada "biodiversidad urbana" (Hough, 1998; Niemelä, 1999; Boada y Capdevilla, 2000) con diferentes abordajes de culto que integran elementos biogeográficos al manejo del paisaje urbano, incluso hay estudios con propuestas y experiencias aplicadas para el AMBA (Burgueño y Nardini, 2009; Garay y Fernández, 2013; Haene, 2018). Asimismo, hay investigaciones que han proporcionado a esta temática planteos sobre comportamientos en la fisiología humana en relación con la percepción y contacto de la naturaleza en las ciudades (Kellert y Wilson, 1999; Kaplan, 1995; Groenewegen et. al., 2006).

Efectivamente, al analizar el soporte material del AMBA se advierte que predomina materiales inorgánicos e infraestructuras verticales y horizontales, como los grandes edificios y el ferrocarril, constatando que en la mayoría de los espacios urbanos poco brindan a la población escenarios para la percepción y comprensión de la naturaleza. Aunque hay otras áreas urbanas donde hay especies presentes de diferente origen, forma y composición, a partir de tres procesos: (1) especies nativas que ya estaban presentes antes de la urbanización, (2) especies nativas que, aunque no se encontraban previamente de forma natural, se han desarrollado en las nuevas condiciones urbanas, y (3) especies foráneas introducidas a través de la actividad humana (Boada y Capdevilla, 2000; McKinney, 2006). Sin embargo, se señala que no todas las especies acaban adaptándose eficientemente al medio urbano, incluso pueden desencadenar procesos invasores dañinos.

Ahora bien, la pandemia nos revela que proyectarse hacia una nueva normali- 
dad plantea que el desafío futuro debería estar alejado de posiciones anti-ciudad, donde la vegetación, los animales y los nichos ecológicos que los soportan en los espacios abiertos urbanos pueden ofrecer beneficios a la población en dimensiones fisiológicas, ecológicas y urbanas. Ese espacio a planificar, siguiendo a (Boada y Capdevilla, 2000) forma parte de espacios verdes (jardines, espacios verdes públicos, parques, etc.), espacios azules (lagos y lagunas, costas y riberas, corredores de arroyos y ríos,) y espacios grises (vías férreas, bordes de avenidas y autopistas, edificios, entre otros). En rigor, cuando se piensa sistémicamente la dotación de una denominada infraestructura ecológica está el propósito de naturalizar la ciudad: contacto con el sol, la tierra, los pájaros, la flora, el agua, todo ello integrado a un paisaje metropolitano. Se trata de una imagen urbana conectada físicamente a su entorno biogeográfico por medio de un mosaico de áreas agrícolas, forestales y pastizales, atravesadas por litorales, ríos, arroyos, bañados, etcétera. En la figura 6 se reconoce los elementos para una articulación socioecológica-espacial preexistentes y nuevos en el territorio metropolitano.
A partir de esta definición, a continuación se repasan sintéticamente aquellos elementos formales y beneficios a poner en valor frente a la amenaza pandémica en el marco de una gestión ambiental metropolitana. Son múltiples los beneficios sociales de una infraestructura ecológica si se piensa liberar suelo para ampliar la distancia física frente al covid-19, como también mejorar la calidad del aire, brindar espacios recreativos, deportivos y escénicos, incluso ampliar modalidades de la movilidad urbana, entre otros usos y funciones ecológicas.

Cada vez se encuentran más investigaciones académicas en todo el mundo que demuestran cómo el contacto con la naturaleza beneficia la salud humana, en particular cómo los espacios verdes en contextos urbanos son coadyuvantes en una buena salud no solo física, sino también mental. La "hipótesis de la biofilia" de Kellert y Wilson (1993) abarca de manera integral las distintas dimensiones del ser humano que obtiene beneficios en la salud con la interconexión con la naturaleza. De ahí surge la caminata terapéutica por el bosque que puede bajar la presión arterial, disminuir la ansiedad, mejorar la concentración y la memoria, reducir la probabilidad de sufrir depresión, hi-

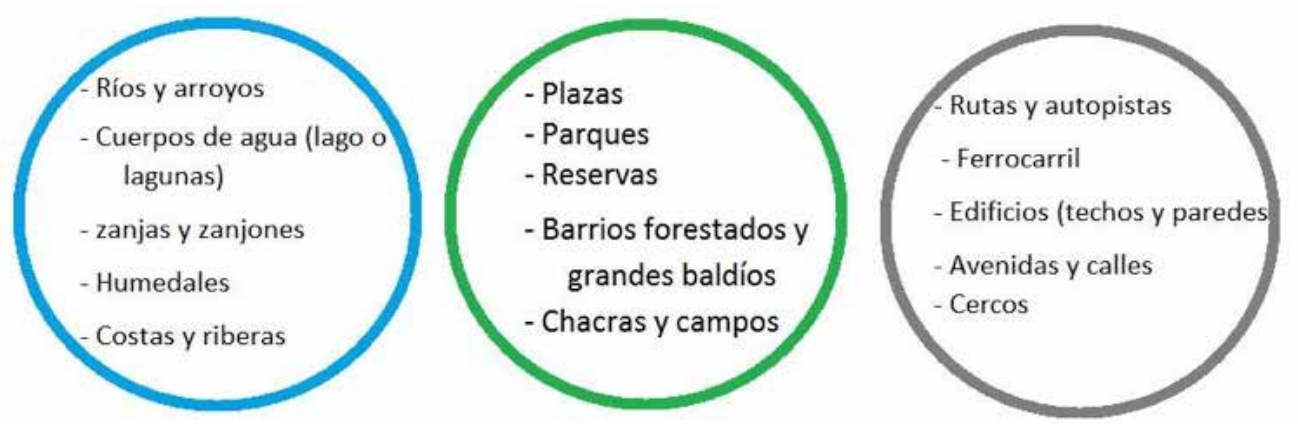

Fig. 6. Elementos de la infraestructura ecológica. Fuente: adaptado de Boada y Capdevilla (2000). 
EL VERDE METROPOLITANO: UNA REVISIÓN DE LOS ESPACIOS ABIERTOS PÚBLICOS EN CLAVE PANDÉMICA PARA EL ÁREA METROPOLITANA DE BUENOS AIRES

pertensión y enfermedades cardiovasculares; incluso hasta prevenir el cáncer. Asimismo, la teoría de la restauración atencional de Kaplan (1995) supone que los entornos naturales poseen la capacidad para restablecer los recursos psicológicos que se han deteriorado por la incompatibilidad de las actividades de la vida cotidiana, sobre todo en la atención dirigida. Por eso los ambientes que no son amenazantes se caracterizan por fascinantes y tienen la propiedad de dirigir nuestra atención sin esfuerzo. La OMS ha publicado estudios que indican los beneficios de la Vitamina D en la salud inmunológica, específicamente en la prevención de infecciones de las vías respiratorias (WHO, 2016). También refiere a la reducción de la pérdida de mineralización ósea, especialmente en mujeres posmenopáusicas. Inclusive la vitamina $\mathrm{D}$ está implicada en otras funciones biológicas de los sistemas musculares, inmunitario, el metabolismo del fósforo y dentario, entre otros. Si bien no está validado por la comunidad científica internacional, existen estudios preliminares que relacionan la vitamina $\mathrm{D}$ con los niveles de letalidad de covid-19. Los datos surgen del cruce de estadísticas en los países europeos con la tasa de mortalidad relativa por el covid-19, marcando que países con mejores niveles de vitamina $\mathrm{D}$ promedio registraron menor cantidad de muertes por el virus. Menos conocido es el rol que juega la denominada Vitamina "G", definido en el concepto de grounded-earthing que hace referencia a los beneficios en la salud el pisar descalzo en la tierra o contacto corporal con ella. Es que el cuerpo humano es conductivo y está compuesto en gran parte por agua y minerales. En este sentido, reducir la desconexión del calzado, superficies de concreto y edificios incrementa el equilibrio eléctrico que necesita el metabolismo humano. En este sentido, hay estudios que demuestran beneficios específicos para la salud en las prácticas de jardinería y de huertos hogareños como niveles reducidos de colesterol. Pero hay evidencias de que pueden contribuir a la salud y bienestar de forma más general con la reducción del estrés, promover la actividad física y establecer un sentido de integración social y cultural con el entorno y que combata el aislamiento social (Groenewegen et al, 2006).

Existen zonas urbanas y áreas de la región que por sus características geográficas brindan ventajas para un aislamiento físico. En esos ámbitos, las reservas naturales urbanas, los parques urbanos, las plazas barriales, incluso barrios de baja densidad con arboledas frondosas brindan un efecto "cortavirus" ya que proporcionan condiciones favorables para el mantenimiento de distancia física interpersonal y el aislamiento. Tengamos en cuenta que hay barrios que en sus geografías urbanas brindan un deslinde por presencia de arroyos, trazados ferroviarios y viales o grandes descampados. En este punto surge un debate si en un marco de apelativos gubernamentales al "aislamiento y distanciamiento, preventivo, social y obligatorio" sería posible favorecer confinamientos más locales para toda un área, ofreciendo autonomía al interior de economías sociales propias: propiciar el aprovisionamiento en comercios y servicios de proximidad con menor densidad de población que en las grandes superficies comerciales de los espacios centrales. En esa perspectiva, la descripción de las tres ecorregiones presentes en el contexto metropolitano (pastizal, espinal, selva) resulta de importancia a la hora de analizar la naturaleza, diseñar y planificación con plantas nativas 

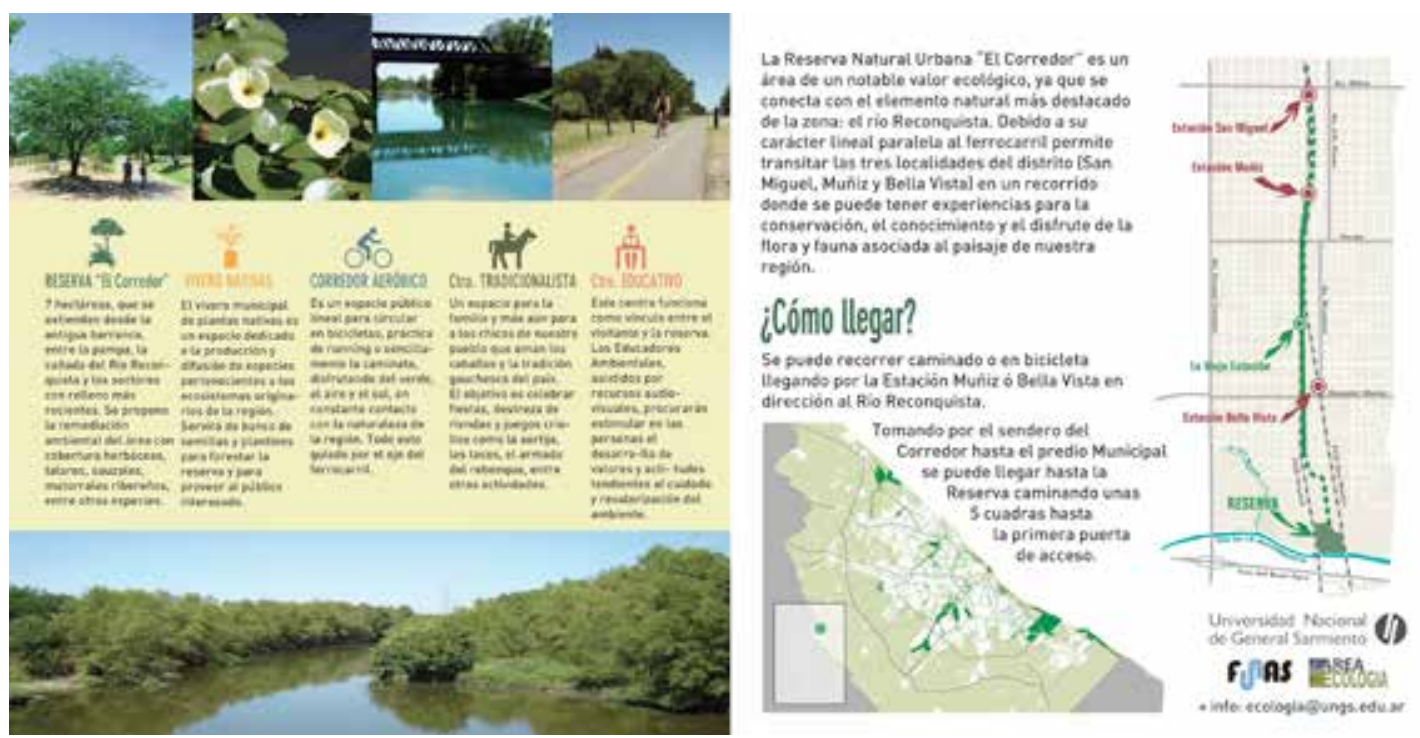

Fig. 7. Reservas naturales urbanas. Una experiencia de investigación-acción elaborada por un equipo de trabajo del Instituto del Conurbano, el Centro de Servicios de la UNGS, y la Fundación de la Universidad Nacional de General Sarmiento articulando con el Municipio de San Miguel y la comunidad durante 2011-12. Fuente: Fernández, Piaggio y Bardelás, 2011.

espacios urbanos, con un enfoque de recrear la naturaleza originaria, fauna silvestre, perfiles escénicos del paisaje natural (Burgueño y Nardini, 2010).

Los árboles, arbustos y pastos cumplen una función "descontaminante" ya que absorben, a través de las hojas, las partículas sólidas o líquidas de la atmósfera como hollín, polvo y cenizas. Las partículas identificadas como material particulado (PM, por sus siglas en inglés) tienen un diámetro no superior a 10 micrones, por lo que penetran directamente en los pulmones provocando efectos dañinos en la salud. La vegetación retiene, acumula, incluso metaboliza en su tejido vegetal el material particulado. También la masa forestal amortigua la contaminación sonora, atenúa los vientos y es refugio de numerosas especies de aves, y en general fauna adaptada al entorno urbano como maripo- sas, insectos, batracios...El uso de plantas nativas en espacios verdes públicos, incluso en pequeños jardines privados, aportan biodiversidad urbana. Estas "islas" de alta biodiversidad resultan hábitats adecuados para muchos animales voladores capaces de vivir en el "archipiélago" ofrecido. La jardinería en pequeños terrenos, por ejemplo, de unos $45 \mathrm{~m}^{2}$ son ámbitos para producir flores, compartir semillas y gajos con vecinos y amigos, cultivar plantas nutricias para criar mariposas, atraer colibries... (Haene, 2018).

Por otro lado, hay innumerables estudios científicos demuestran que un aumento de la naturaleza en el entorno urbano brinda condiciones clave para la salud (World Health Organization \& Convention Biological Diversity, 2015). Además, hay que tener presente que el periurbano del AMBA la calidad productiva de la tierra y las condiciones climá- 
EL VERDE METROPOLITANO: UNA REVISIÓN DE LOS ESPACIOS ABIERTOS PÚBLICOS EN CLAVE PANDÉMICA PARA EL ÁREA METROPOLITANA DE BUENOS AIRES

ticas a nivel regional son formidables, sobre todo, si se piensa en la protección de tierra no edificable para el despliegue de agricultura urbana, destacando no sólo la valoración de la tierra periurbana en los flujos de energía y alimentos esenciales que sustenta la producción y abasto de alimentos para la ciudad (Barsky, 2005, 2020), sino también en la producción de alimento con huertos hogareñas y comunitarias en áreas densamente pobladas. Existen programas nacionales (Pro-Huerta), provinciales y municipales con valiosas prácticas en la producción de huertas agroecológicas para la producción de alimentos saludables. En zonas pampeanas ${ }^{3}$ del periurbano bonaerense el potencial productivo del suelo fértil es formidable: se encuentra los índices de I a IV definidos por el Servicio de Conservación del Suelo de Estados Unidos (USDA) como recurso natural irreemplazable, apto para cultivos agrícolas. El cinturón verde del AMBA refiere a la horticultura de proximidad, llevada a cabo históricamente por migrantes de orígenes diversos: españoles, italianos, portugueses y, hoy en día, bolivianos (Barsky, 2005). La pérdida de suelo fértil debida a la expansión urbana es un tema de preocupación en la política de manejo del suelo, especialmente porque la nueva urbanización se desarrolla fundamentalmente en suelos de vocación agrícola.

3 La pampa es un "mar" loseico mundial que tiene una extensión de 50 millones de hectáreas y representa un recurso natural fundamental para el despliegue productivo del país. Se trata de una gran estepa herbácea con temperaturas benignas para el desarrollo agrícola, lluvias repartidas durante todo el año, y suelos profundos con un alto contenido de materia orgánica.
Conceptualmente la energía endosomática es generada por el metabolismo humano a través de los alimentos consumidos y posibilita el despliegue de actividades vitales, como los desplazamientos pedestres, prácticas aeróbicas o movilidad en bicicleta. La movilidad basada exclusivamente en energía endosomática representa una forma eficiente en relación al uso de energía exosomática en la que se apoya el transporte urbano (combustibles). Curiosamente, en el contexto de la pandemia, asistimos a un vuelco a desplazamientos individuales no motorizados, evitando las restricciones impuestas al aglutinamiento en el transporte público y la conservación de la baja densidad de población. En ese sentido, en la región impulsar modalidades saludables y ecológicas de movilidad urbana en esos lugares, a pesar de que implican mayor inversión de tiempo y esfuerzo físico para llevarlo a cabo, representan verdaderos activos espaciales. Por ejemplo, incorporar ciclovías, corredores aeróbicos y sendas peatonales sobre un eje lineal abierto, como las márgenes de las trazas ferroviarias o viales ofrecen condiciones de desplazamiento ciudadano, de la instalación de equipamiento social, incluso para restablecimiento del paisaje nativo. Esas trazas brindan importantes conexiones barriales entre estaciones que en muchos tramos de la geografía se encuentran desaprovechados. Además, los elementos del mobiliario colocados en ese espacio público son "referencias" que pueden articular usos ciudadanos y, a la vez, contacto con el sol, con los pájaros, con la vegetación regional, con los arroyos urbanos que surcan el recorrido, etcétera. En ese recorrido, además de resolver desplazamientos, nos hace partíci- 
pes de experiencias urbanas en contacto con elementos naturales. Un parque lineal verde, pensemos, entre 10 a 50 metros de ancho, articulando una distancia urbana continua, no sólo conecta áreas urbanas aisladas o autónomas, sino genera un "deslinde", una frontera verde de amortiguación (buffer). Sólo considerando la morfología que ofrecen las trazas del sistema ferroviario metropolitano existen un poco más de 800 kilómetros lineales continuidad física con un acervo de historias, ramales, trochas y estaciones distribuidas en toda la geografía metropolitana.

La importancia de conceptualizar una "biodiversidad metropolitana" está en el restablecimiento de las condiciones originales del pastizal pampeano, los bosques de talares y la selva marginal. La topología que dotan los corredores biológicos para el desplazamiento de determinadas especies, o cinturones verdes con parques y reservas a escala metropolitana, pueden configurar en el tejido urbano entrelazada de información biológica de valor ambiental. En el contexto de la pandemia de covid-19 estos ámbitos brindan, por su propia condición geográfica, un factor de aislamiento físico en relación a otras áreas. Finalmente, hay estudios que alertan sobre las incertidumbres planetarias e impactos regionales que genera el denominado cambio climático, señalando los escenarios y desafíos actuales que enfrenta la planificación de las ciudades. Precisamente, el Panel Intergubernamental sobre el Cambio Climático (IPCC según sus siglas en inglés) pronostica aumentos en la intensidad, duración y frecuencia de las lluvias torrenciales, las inundaciones, las olas de calor y las sequías de larga duración, entre otros fenómenos climatológicos (IPCC,
2014). Las ciudades con una mayor diversidad biológica son más resilientes frente al cambio climático y ofrecen una serie de servicios ecosistémicos. La mitigación/adaptación al cambio climático, se vincula con medidas como la dotación de espacios verdes de amortiguación y mitigación de lluvias torrenciales extraordinarias, o reservorios paliativos a la escasez de agua y amortiguamiento al aumento de las temperaturas, regulación de caudales de pulsos de inundaciones, en entre otras funciones. La perspectiva de una infraestructura ecológica supone proteger espacios estratégicos para la mitigación/adaptación frente al cambio climático y procesos de crecimiento metropolitano. También es una herramienta de gestión para enfrentarse a los efectos del cambio climático y poder guiar el desarrollo de los planes urbanos municipales. Tengamos en cuenta que una contingencia climática con impactos en inundaciones o de escasez de agua en el contexto de la pandemia puede combinar efectos aún más devastadores para la población sometida al aislamiento físico.

Recapitulando con las referencias memorables de la sección anterior, la definida infraestructura ecológica evoca desde el higienismo decimonónico que practicó Sarmiento hasta el sanitarismo de Pistarini de la década de 1940. Aunque dotando valores y significados nuevos si se piensa ecológicamente los espacios verdes para un diseño escénico con plantas nativas o restablecimiento de las condiciones naturales de grandes espacios para mitigación/adaptación al cambio climático. Agreguemos que se asoman elementos del urbanismo de Della Paolera o de Le Corbusier que plantearon ideas para los problemas de las ciudades de su tiempo. Aun- 
EL VERDE METROPOLITANO: UNA REVISIÓN DE LOS ESPACIOS ABIERTOS PÚBLICOS EN CLAVE PANDÉMICA PARA EL ÁREA METROPOLITANA DE BUENOS AIRES

que a los problemas de higiene, de movilidad y de acceso al espacio público de aquella época la pandemia le ha dotado en nuestra ciudad actual, diferentes sentidos y agregando nuevos usos esenciales.

\section{DISCUSIÓN}

Podría señalarse que la pandemia puso en crisis el impulso concentracionista, congestivo y de organización interjurisdiccional que caracteriza al AMBA. El imperativo epocal de la distancia física que evite contagios de covid-19 y los argumentos ecológicos, sanitarios y formales que reúne el texto permiten colocar conceptualmente la importancia de una infraestructura ecológica. Los argumentos históricos, ecológicos y metropolitanos reunidos sobre los espacios abiertos públicos permiten poner en contexto la influencia que esta temática tiene en tiempos de pandemia y tendrá de cara a una postpandémica. Los intereses que pugnan en ampliar el acceso a los espacios abiertos, están representados fundamentalmente en la ciudadanía, en municipios, en la gobernación bonaerense, en la jefatura porteña, en el gobierno nacional, en la opinión pública, en las ONG's ambientales, en agencias gubernamentales, en organismos de cooperación internacional... Si bien hay algunos municipios que han realizado experiencias exitosas, la gran mayoría han tenido muchas dificultades al momento de fijar políticas de escala metropolitana y estrategias de gestión local relacionados con instrumentos de manejo del suelo, como aspectos legales, financieros y económicos para su implementación, y en general el problema de la falta de conocimiento sobre la temática y capacidad de gestión para el manejo del suelo urbano.

Precisamente al reunir referencias memorables de los grandes espacios abiertos en la región se pudo brindar diversos puntos de vista en dimensiones ecológicas, formales y representacionales. Como la que refiere a la inspiración corbuseriana de Buenos Aires con una línea del Río de la Plata y la infinitud de la pampa, o el planteo ecuménico de Della Paolera con el sol, el aire, la vegetación para concebir el urbanismo para el "Gran Buenos Aires”. También está la reivindicación que hacía el peronismo a los trabajadores en el acceso y disfrute de grandes espacios abiertos, balnearios y equipamiento sanitario en el conurbano. O las representaciones en el paisaje bonaerense que remiten a la prosa sarmientina y el higienismo con los Bosques de Palermo, o su traducción castrense en un cinturón verde como dispositivo de ordenamiento metropolitano. No encontramos una línea histórica en el tema de estudio, ni continuidades de proyectos políticos en el territorio, pero sí hay rupturas de discursos, hay problemas que persisten, hay condiciones del medio físico que atrapan. Quizás con una pretensión laudatoria de perspectivas regionales propias, hay formas ecológicas que se reconocen en el urbanismo de Della Paolera en el contexto metropolitano. Y también está Le Corbusier, en la escala urbanística, imprimiendo en el paisaje urbano no sólo ese impulso obsesivo de cara al Río de la Plata, sino el contacto con la extensa, biodiversa $y$ fértil planicie bonaerense. $Y$ acaso en esas actitudes se percibe en el paisaje dos planos de intervención, a veces articulados entre sí: uno más biológico (con énfasis en lo corpo- 


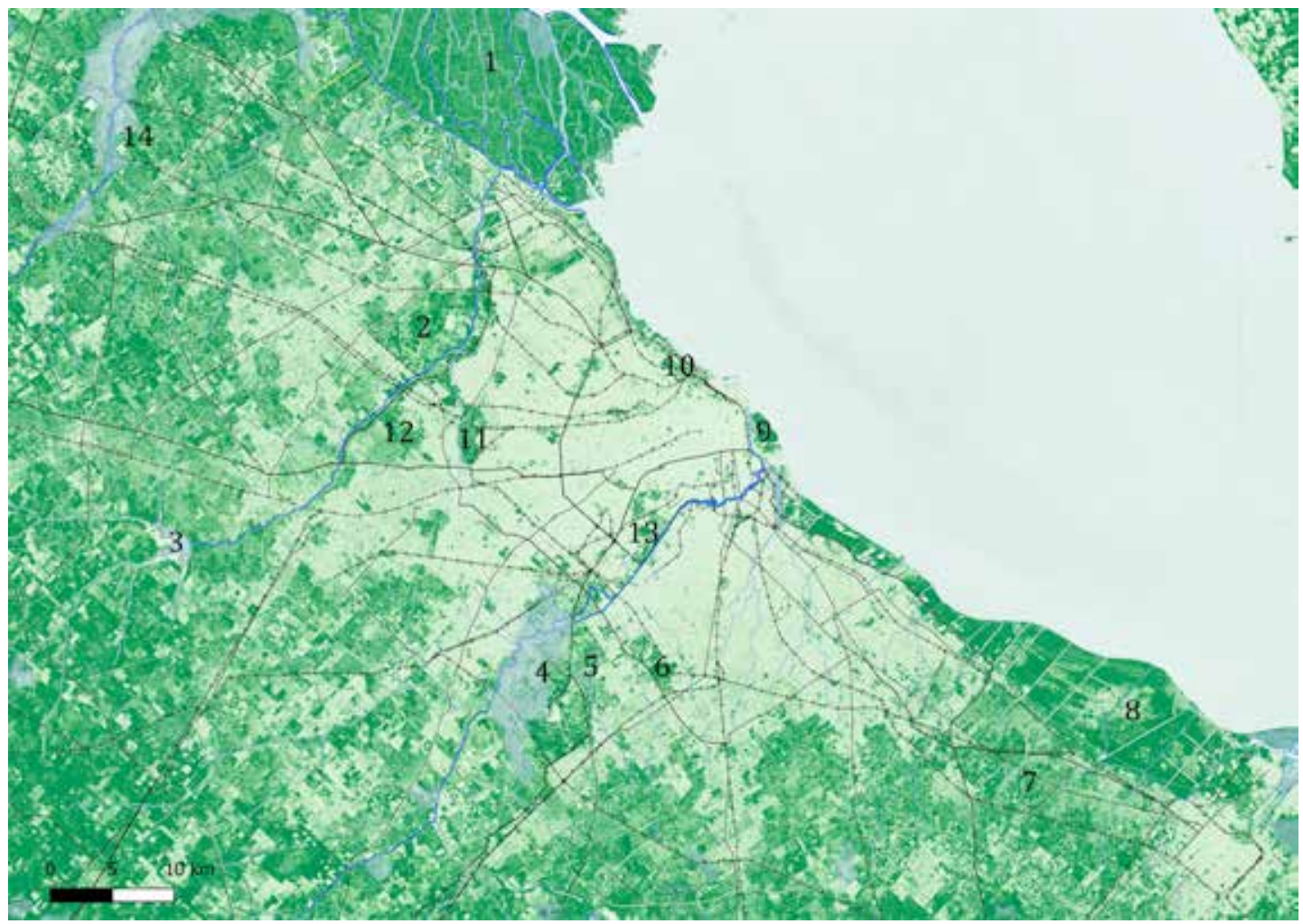

Fig. 8. El verde metropolitano. 1: Delta, 2: Campo de Mayo, 3: Dique Roggero, 4: Bosques de Ezeiza, 5: Laguna Rocha, 6: San Catalina, 7: Pereyra Iraola, 8: Reserva Hudson, 9: Reserva Costanera Sur, 10: Bosques de Palermo, 11: Palomar, 12: Inta Castelar, 13: Parque Almte. Brown, 14: Reserva Natural Pilar. Fuente: Imagen satelital: CONAE, 9-05-2020. Plataforma: Satélites Aqua \& Terra Instrumento: MODIS Sensor: MODIS Proveedor: NASA - EOSDIS. Capa vectorial: IGN Proyecto SIG-250 (capas shape file: cursos de agua, cuerpos de agua, ferrocarriles y rutas)

ral, en lo ecológico) y otro más situacional (marcado por lo espacial y estratégico).

Ahora bien, se sostiene la posibilidad de ensayar en clave sistémica un conjunto de formas ecológicas para el AMBA. El enfoque ecosistémico comprende a la temática de las áreas verdes como parte integrada de una complejidad metropolitana, rioplatense y pampeana. En este sentido, supone la captura de suelo para el verde metropolitano, tal como plantea Garay y Fernández (2013), mediante la conexión de espacios libres inter- nos con los espacios naturales (humedales, bosques, costas, riberas, arroyos) y rurales periféricos. El objetivo del planteamiento es la creación de una red de espacios interconectados por medio de nodos, corredores y envolventes. En este sentido, el Índice Diferencial de Vegetación Normalizado, conocido por sus siglas en inglés como NDVI, permite ponderar en la región el estado fotosintético de la vegetación (figura 8), combinando dos bandas situadas en el espectro visible "concretamente el rojo" y en el infrarrojo próxi- 
EL VERDE METROPOLITANO: UNA REVISIÓN DE LOS ESPACIOS ABIERTOS PÚBLICOS EN CLAVE PANDÉMICA PARA EL ÁREA METROPOLITANA DE BUENOS AIRES

mo. ${ }^{4}$ Esas dos zonas espectrales, mediante el procesamiento de imágenes satelitales de la CONAE (Comisión Nacional de Actividades Espaciales), muestran las diferencias entre la vegetación sana y vigorosa, con alto contenido de humedad (verde intenso) y la vegetación enferma, que no muestra actividad fotosintética (verde degradado). De ahí que la expresión gráfica ponderada permite identificar áreas con suelos de vegetación y áreas edificadas considerando también la presencia de diferentes cuerpos de agua. Superponiendo esa imagen del NDVI están las capas vectoriales del IGN (Instituto Geográfico Nacional) con los cursos de agua, cuerpos de agua, la red ferroviaria y la red vial metropolitana.

De acuerdo a estos resultados geográficos, se destacan las siguientes áreas de actividad fotosintética de valor regional para una infraestructura ecológica:

- la red hidrográfica, incluyendo el frente ribereño (río, arroyos, pajonales, lagunas)

- las grandes áreas de forestación vigorosa y vegetación (reservas, parques y barrios de forestación frondosa)

- el borde periurbano (áreas de flori, fruti y horticultura).

En contrapartida, se verifica menor actividad fotosintética en las áreas urbanas, donde se destacan las áreas densamente urbanizadas, la red de caminos (avenidas, rutas y autopistas) y el ferrocarril.

De acuerdo a este tipo de lectura podemos definir con un sentido práctico y

4 Se seleccionaron y procesaron imágenes satelitales disponibles desde la web de la CONAE (https:// catalogos.conae.gov.ar/). El procesamiento y análisis de imágenes fueron realizadas con el software QGIS 3.6. funcional la infraestructura ecológica en el AMBA en base a su ubicación en el relieve, su origen (antrópico o natural) y la vegetación dominante. Las tres eco regiones presentes en el área de estudio forman una secuencia de diferentes ambientes conectado al área urbana, el pastizal, ríos, arroyos, bosques de tala, selva, pajonales y lagunas (Burgueño, 2014). En líneas generales la topología de una infraestructura ecológica encuentra con las reservas, parques y corredores opciones diferentes de "espacios verdes" con diversas formas y conexiones naturales: una reserva natural como "pulmón" regional se asocia al frente rioplatense (Reserva Costanera Sur, Reserva Hudson, Reserva Otamendi) o borde periurbano pampeano (Reserva Santa Catalina, Laguna Rocha, Dique Roggero), un parque metropolitano como "amortiguador" (Bosque de Ezeiza, Bosque de Palermo, Parque Pereira Iraola,) en "cuñas" verdes de la urbanización metropolitana (Bosque de Ezeiza, Campo de Mayo, Pereira Iraola, Reserva Hudson) actúan como deslinde de la pampa y la urbanización; un parque lineal como "conector" se asocia a elementos geográficos de "espacios azules" como un río, arroyos, lagunas o frente litoral (Laguna Rocha, Costanera Sur, Laguna ex Batallón), incluso una "espacios grises" con elementos geográficos como una traza ferroviaria, vial o líneas de media y alta tensión (Ferrocarril Belgrano Norte, San Martín, etcétera).

La "hipótesis de la biofilia" (Kellert y Wilson, 1999) y la teoría de "restauración atencional" (Kaplan, 1995) demuestran cómo el contacto con la naturaleza beneficia la salud humana. Investigaciones han demostrado relaciones positivas entre la presencia 
de vegetación en ámbitos hogareños y zonas urbanas en la salud de la población. La exposición de la piel al sol (vitamina D) y el contacto de los pies desnudos con la tierra (vitamina "G") -acompañado por una dieta saludablees una forma de metabolizar nutrientes esenciales y lograr bienestar fundamental. Existen áreas y conjuntos de la región (reservas naturales urbanas, los parques urbanos, las plazas barriales, incluso barrios de baja densidad y arboledas frondosas) que brindan por sus características geográficas un efecto "cortavirus" ya que proporciona condiciones favorables para la distancia física interpersonal. Complementariamente, la incorporación de ciclovías, corredores aeróbicos y sendas peatonales sobre ejes lineales abiertos, como las márgenes de las trazas ferroviarias o viales ofrecen condiciones de desplazamiento ciudadano, además de la instalación de equipamiento social. Además, la perspectiva de una infraestructura ecológica en grandes áreas libres proporciona condiciones para el restablecimiento del paisaje nativo (pastizal, bosque y espinal), especialmente estratégicos frente al cambio climático: medidas para la mitigación/adaptación de lluvias extraordinarias, manejo de la inundación en las cuencas superiores, y amortiguamiento al aumento de las temperaturas, entre otras.
El impacto de la pandemia interpela el escenario actual en pos de lograr más espacios abiertos públicos, menos contaminación, menos ruidos para llevar a cabo usos esenciales en la reproducción de la vida en las ciudades. El apelativo gubernamental de una "nueva normalidad" (Presidencia de la Nación, 2020) implica incorporar políticas públicas en relación a los espacios libres. Pero es una deuda social que, además de criterios sanitarios, sean inclusivas en el acceso a los espacios abiertos públicos. En este marco, es posible repensar las infraestructuras ecológicas en perspectiva histórica y aplicando nuevos criterios que respondan a las necesidades esenciales de la población. En este sentido, reconocemos una gobernabilidad en relación al verde metropolitano que refiere a las estrategias de naturalización invocadas en este texto. Se trata de una forma de gobernabilidad que complementa con un abanico muy amplio de circuitos de gestión política y participación ciudadana en la gestión ambiental metropolitana. Es una cuestión que exhorta a renovar la concepción dominante acerca de las políticas de inversión pública en infraestructura. Porque el desafío de este tiempo no es sólo la distancia física mientras dure la amenaza del covid-19, sino crear espacios más democráticos de la ciudadanía en la post-pandemia. 
EL VERDE METROPOLITANO: UNA REVISIÓN DE LOS ESPACIOS ABIERTOS PÚBLICOS EN CLAVE PANDÉMICA PARA EL ÁREA METROPOLITANA DE BUENOS AIRES

\section{REFERENCIAS}

Alberti M. Advances in Urban Ecology: inter-preting humans and ecological processes in Urban Ecosystems. Washington: University of Washington, 2009.

Ballent, A., Las huellas de la política: vivienda, ciudad, peronismo en Buenos Aires, 19431955, Quilmes: Universidad Nacional de Quilmes / Prometeo 3010, 2005

Bettini V. Elementos de Ecología Urbana. Madrid: Ed. Totta, Serie Medio Ambiente, 1998.

Boada M. y L. Capdevilla. 2000. Barcelona: biodiversidad urbana. Barcelona: Ajuntament de Barcelona, 2000.

Barsky, A. Las tensiones del abasto alimentario del AMBA frente al COVID-19. En La gestión de la crisis en el Conurbano Bonaerense. Edición Especial COVID-19, Observatorio del Conurbano. Los Polvorines, Instituto del Conurbano, Universidad Nacional de General Sarmiento, Argentina, 2020.

Barsky A. "El periurbano productivo, un espacio en constante transformación. Introducción al estado del debate, con referencias al caso de Buenos Aires". Scripta Nova. Revista electrónica de geografía y ciencias sociales. [En línea]. Barcelona: Universidad de Barcelona, 1 de agosto de 2005, vol. IX, núm. 194 (36), available at: <<http://www.ub.es/geocrit/ sn/sn-194-36.htm > accessed 9 Jul 2021.

Batty, 2008. "The Size, Scale, and Shape of Cities". Science 319, (2008): 769-771
Burgueño G. y C. Nardini. Introducción al Paisaje Natural, Buenos Aires: Ed. Orientación Gráfica, 2009.

Burgueño, G.. Restauración del paisaje metropolitano. Apuntes para la reflexión y planificación en la Región Metropolitana de Buenos Aires. Buenos Aires: Ed. Orientación Gráfica, 2014.

Caride Bartrons, H. “Ciudad, urbanismo y ecología urbana". En Di Pace, María, Ecología de la ciudad. Buenos Aires: Prometeo-UNGS, 2004.

Comisión de Estética Edilicia de la Intendencia Municipal de Buenos Aires, Proyecto Orgánico para la Urbanización del Municipio. El Plano Regulador y de Reforma de la Capital Federal, Talleres Peuser, Buenos Aires, 1925.

Corti, M. "Las preguntas de la baja densidad". Café de las ciudades \#(2) 197 - Mayo de 2021.

Della Paolera, C. M. "Buenos Aires no tiene noción de los espacios libres" Conferencia en la Facultad de Ciencias Exactas, Físicas y Naturales de la Universidad de Buenos Aires, 5 de junio de 1933. In Della Paolera, Carlos, Buenos Aires y sus problemas urbanos. Buenos Aires: Oikos, 1977

Della Paolera, C. M. "El símbolo del urbanismo". Dirección del Plan de Urbanización. Municipalidad de la Ciudad de Buenos Aires. Folleto, Noviembre de 1934.

Di Pace M. (directora) y H. Caride Bartrons (editor). Ecología urbana. Los Polvorines: Ed. UNGS, 2012. 
Fernández, L, S. Piaggio y A. Bardelás Proyecto Reserva Natural Urbana El Corredor, Instituto del Conurbano-Centro de Servicios-Fundación de la UNGS. Programa de Servicios No Rentados a la Comunidad, 2011.

Fernández, L.,"Urbanismo y ecología en Buenos Aires: un recorrido por la planificación urbana en su contexto ecológicoregional". urbe. Revista Brasileira de Gestão Urbana (Brazilian Journal of Urban Management), 2016 jan./abr., 8(1), 12-27.

Fernández, L., La muralla verde: Urbanismo y ecología en tiempos de dictadura en el Gran Buenos Aires (1976-1983). Los Polvorines: Ed. UNGS, 2020.

Garay D. y L. Fernández. Biodiversidad urbana. Apuntes para un sistema de áreas verdes en la región metropolitana de Buenos Aires. Los Polvorines: Ed. UNGS, 2013.

Gorelik, A. Miradas sobre Buenos Aires. Historia cultural y crítica urbana. Buenos Aires: Siglo XXI, 2004.

Gorelik, A. La grilla y el parque, Quilmes: Universidad Nacional de Quilmes, 1999.

Haene, E. "Los jardines con plantas nativas aportan biodiversidad urbana. Estudio de caso en la Ciudad Autónoma de Buenos Aires, Argentina". Perspectivas (Universidad de Belgrano), 2018, 1 (1).

Hough M. Naturaleza y ciudad: planificación urbana y procesos ecológicos. Barcelona: Editorial Gustavo Pili, 1998.

Intergovernmental Panel on Climate Change (IPCC). Climate change 2013: The physical science basis: Working group I contribution to the fifth assessment report of the intergovernmental panel on climate change. New York: Cambridge University Press, 2014.

Kaplan, S. "The restorative benefits of nature: Toward an integrative framework". Journal of Environmental Psychology. 15 (1995): 169-182.

Kellert S. R. y E. O. Wilson, The Biophilia Hypothesis. Washington, DC: Island Press, 1999.

Laura, G., El cinturón ecológico, Buenos Aires: CEAMSE, 1978.

Le Corbusier, 1954, La Carta de Atenas, Buenos Aires: edición de la Municipalidad de la Ciudad de Buenos Aires (primera edición 1942).

Le Corbusier, J. Kurchan y J. Ferrari Hardoy, 1947, "Plan Director para Buenos Aires", separata de L'Architecture D'Aujourd'hui, Buenos Aires (versión castellana).

Le Corbusier. Sur les quatre routes. París, 1941.

Liernur, J. F.. Arquitectura en la Argentina del siglo xx. La construcción de la modernidad. Buenos Aires: Fondo Nacional de las Artes, 2001.

Niemelä, Jari. “Ecology and urban planning”. Biodiversity and Conservation 8 (1999): 119-131.

Novick, A. "La avenida más ancha del mundo. Política, arquitectura e imagen". Anales del Instituto de Arte Americano e Investigaciones Estéticas "Mario Buschiazzo" Facultad de Arquitectura, Diseño y Urbanismo, Buenas Aires, 2011, Vol. 41, No 2. 
EL VERDE METROPOLITANO: UNA REVISIÓN DE LOS ESPACIOS ABIERTOS PÚBLICOS EN CLAVE PANDÉMICA PARA EL ÁREA METROPOLITANA DE BUENOS AIRES

Novick, Alicia. "Plan" y "Della Paolera, Carlos María”. En Liernur, Jorge y Aliata, Fernando (dirs.), Diccionario histórico de arquitectura, hábitat y urbanismo en la Argentina. Buenos Aires: sca, ceadig, iaa, fadu-uba, 1992.

Mckinney, M.L. "Urbanization as a major cause of biotic homogenization". Biological Conservation, 127 (2006): 247-260.

Outtes, J. "Disciplinando la sociedad a través de la ciudad: El origen del urbanismo en Argentina y Brasil (1894-1945)". EURE (Santiago) [en línea]. 2002, 28(83).

Peter P Groenewegen, Agnes E van der Berg, Sjierp de Vries y Robert A Verheij, "Vitamin G: effects of green space on health, well-being, and social safety", BMC Public Health, 2006.

Presidencia de la Nación. Palabras del Presidente de la Nación, Alberto Fernández, por el acto de inauguración de las obras de ampliación del edificio del Departamento
Judicial Avellaneda/Lanús, en Avellaneda, Provincia de Buenos Aires, 3 de noviembre de 2020.

Presidencia de la Nación. La Nación Argentina Justa, Libre y Soberana. Buenos Aires: Peuser, 1950.

Rueda, S. Ecología Urbana, Barcelona: Editorial Beta, 1995.

Scatolini, L., Duarte J. I. y Giménez Hutton, T. Hábitat, un desafío para todos. La Plata: Editorial Universidad Nacional de La Plata, 2020.

Terradas J. 2001. Ecología Urbana. Barcelona: Rubes Editorial, 2001.

World Health Organization. Urban green spaces and health. A review of evidence. Copenhaguen: WHO Regional Office for Europe, 2016.

World Health Organization \& Convention on Biological Diversity. "Connecting global priorities: biodiversity and human health: a state of knowledge review". Geneva: WHO Press, World Health Organization.

enfocados en la Región Metropolitana de Buenos Aires. Ha publicado diversos trabajos sobre ecología, urbanismo e historia ambiental, entre ellos "La muralla verde" (2020) y "Biodiversidad Urbana” (Garay y Fernández, 2013). Como profesional y consultor participó en programas de cooperación internacional y en la gestión pública municipal, provincial y nacional en temas de planificación territorial e inversión pública de infraestructura. 